\title{
Biosimilar insulin as an alternative for the original products
}

\section{ABSTRACT}

The medical knowledge makes a great progress in methods of treating diseases that makes our life much longer. Diabetes is a typical disease of civilization affecting more and more people all over the world. The cost of insulin therapy constitutes a great part of all expenditures associated with the treatment of patients with diabetes mellitus type 1 and type 2 . Nowadays, when the patents covering biological insulins expire, new possibilities of using biosimilar insulins in treating diabetic patients appear. What is more, this group of products seems to be very promising.

The authors describe, how the biopharmaceuticals and biosimilar drugs started to be used in the treatment. They present the similarities and differences between the biosimilars, original drugs and also generic products, with taking special interest in immunogenicity and the safety profile. The authors also point out the potential advantages and the risk of possible side effects of using biosimilar insulins in patients suffering from diabetes. (Clin Diabetol 2016; 5, 4: 123-126)

Key words: biopharmaceuticals, biosimilar drugs, biosimilar insulins

\section{Introduction}

The medicine makes a great progress in the treatment methods that significantly prolong our life. Un-

Address for correspondence:

dr n. med. Beata Łącka-Gaździk

Katedra i Klinika Chorób Wewnętrznych, Diabetologii i Nefrologii

SUM, Katowice

e-mail: lacka@onet.pl

Translation: GROY Translations

Clinical Diabetology 2016, 5, 4, 123-126

DOI: 10.5603/DK.2016.0021

Received: 19.02.2016

Accepted: 19.09.2016 fortunately, this involves also a greater consumption of drugs required to balance homeostasis disorders.

A typical example of a disease of civilization is diabetes mellitus which affects more and more people. Only in Poland, 3 million people suffer from diabetes mellitus and they require treatment with antidiabetic drugs, including insulin. At first, for several dozen years, insulin was obtained from the pancreas of beef and pork. Insulins obtained by this method were not in full compliance with human insulin. The amount of insulins obtained in this manner was limited. In many cases, this type of insulins were inducing allergies.

In the eighties of the last century, human insulins obtained by genetic engineering appeared on the market. These drugs were thoroughly tested in terms of their action and induced side effects.

Currently, biosimilar drugs are available on the market, including insulin. The following paper presents what kind of medications they are, what type of side effects are associated with their use, and what can be their importance in treatment.

\section{Biopharmaceutical - what is it?}

Biopharmaceutical, also known as biological medical products were introduced to the medical market in the eighties of the twentieth century. These drugs contain one or few substances produced or secreted by live cells [1]. Usually, these products replace or supplement the naturally produced proteins. This group includes products obtained by modern biotechnological methods, such as recombinant proteins, vaccines, monoclonal antibodies, gene transfer products and products for somatic cell therapy, and also synthetic polypeptides, synthetic oligonucleotides prepared by chemical synthesis as well as conventional biological drugs (e.g. blood products, toxins and sera) which are not obtained by advanced biotechnological methods [2]. These drugs are produced by biotechnological methods of DNA recombination, and contrary to 
chemical drugs, they have a complex structure which is difficult to be fully characterized with physical and chemical methods. The differences in the structure with a higher reaction order may entail differences in the biological activity of active substances with the same chemical formula, and thus, cause differences in the effectiveness and safety of medicinal products [3].

The group of first-generation biopharmaceutical includes products that are copies of endogenous human proteins, e.g. insulins, growth hormone or erythropoietins. The first biopharmaceutical officially registered and approved for therapeutic use was human insulin produced from recombined DNA. Humulin (developed by Genentech, produced and licensed by Eli Lilly and Company) is available on the market since 1982. Afterwards, a human recombined erythropoietin was used, and then monoclonal antibodies as well as cytokines.

The latest generation of biopharmaceutical consists of antisense molecules which can interfere with the communication process that leads to the production of unwanted proteins by cells. The first drug of this group - antisense oligonucleotide, was used in the treatment of retinitis caused by cytomegalovirus infection in patients suffering from Acquired Immune Deficiency Syndrome [4].

It is estimated that currently, there are more than 130 biopharmaceutical and hundreds are under research. In order to introduce a medicinal product into the market, it is required to submit chemical-pharmaceutical and biological, pharmacological-toxicological and clinical documentation to relevant registration authorities. A full range of data is required only in relation to the original products. After the expiration of the period of data exclusivity, their copies (that is generic drugs) can be put on market without the need to submit the results of pharmacological, toxicological and clinical tests, except for the bioequivalence study [2].

\section{Biosimilar drugs - what is it and how do they differ from the original drugs?}

Currently, a lot of biological drugs of first generation cease to be covered by a patent and thus, the global market of biological products opens for the so-called biosimilar drugs.

The term "biosimilar" means "a new biological product similar (but not identical) to the already approved drug". Such proteins cannot be and never are $100 \%$ identical to the original protein. It is possible to fully characterize the structure and production process of small-molecule compounds, however it is impossible in case of large biological molecules, e.g. products based on the structure of monoclonal antibodies. The produced medicine cannot be fully biotechnologically characterized, and it means that it is impossible to ex- actly reproduce the original drug [5-8]. There is a clear difference between the generic drugs and biosimilars. The commonly used term "biosimilar" arises from a difficulty to evidence an equivalent efficiency and safety of these drugs, as in case of generic drugs. The protein structure makes it impossible to show the biological equivalence only by methods applied to generic drugs, in particular those with small molecular weight [2].

The distinction between biosimilar and generic drugs is of vital importance for practical reasons and physicians should be well-trained in this scope. Each physician should be aware of the fact that these drugs are not exact copies of the original preparations, as it is in case of generic chemical drugs, but these are biotechnological drugs, the structure of which and their function only imitate the originals. The reason for the differences is, in particular, the fact that each time another cell line, another production and purification process in their preparation is used. As already mentioned above, it is possible to copy chemical drugs because they have a specific structure that can be described as a chemical formula. In contrast, the unique multidimensional structure of proteins constituting biopharmaceuticals cannot be described by a formula, even the most complex. Likewise, it is impossible to fully reproduce the mechanisms of action of drugs, even if the same type of cells is used for production of a particular pharmaceutical. Therefore, we should always expect that some differences will occur in the pharmacokinetic and pharmacodynamics properties of biosimilar drugs in comparison to the original medicines. It was confirmed, for example, by comparing the content of the preparation and potential of various recombined erythropoietins alfa produced outside the EU and USA $[9,10]$.

The safety profile of biosimilars is obviously different from the original drugs [11]. Generally, all therapeutic proteins elicit, to some extent, the immune response. Immunogenicity is one of the most significant features determining the safety of a biological product. The immune reaction after administration of a drug is unpredictable and very diverse (sometimes even lifethreatening). There are many factors determining the occurrence of immunogenicity: individual characteristics of the patient, progression of a disease, and even the therapy itself. Due to the fact, that the biosimilar drugs can be potentially immunogenic (as opposed to the small-molecule pharmaceuticals), even slight structural changes can significantly affect the immunogenic potential of the final product $[12,13]$.

It also seems that it would be a good solution if biosimilar drugs get another international name than the originals. This would prevent an automatic substitution of these substances, and the drugs would have to be subject to a full cycle of preclinical and clinical tests 
before their marketing. Thus, it would have a positive impact on the safety of their use. Marking of biosimilar drugs on their packaging should also clearly distinguish biosimilars from the original drugs [8].

In the current context of increasing financial constraints and due to expiration of patents protecting the biological drugs, biosimilar pharmaceuticals certainly constitute a group of products with a great future. It seems that they offer high quality and clinical efficacy together with a significantly lower price than the originals. Prevalence of these drugs may significantly lower the costs of treatment and contribute to savings in the health care systems. That is why, wide availability of biosimilar drugs may bring benefits not only in terms of health but also economic advantages.

Biosimilars are already used in many fields of medicine, such as endocrinology, rheumatology, gastroenterology, neurology, haematology or oncology. The representatives of this type of drugs were registered for the first time in Europe in 2006. That was Omnitrope (equivalent of Genotropin) and Valtropin (equivalent of Humatrope) for treatment of short in stature. In subsequent years, biosimilars of recombined human erythropoietin, G-CSF granulocyte colony-stimulating factor (filgrastim) and human growth hormone (somatropin) were also made available. In 2013, a biological biosimilar drug containing monoclonal antibody was registered for the first time. It contains infliximab which has been used in treatment for several years already, e.g. rheumatoid arthritis, ankylosing spondylitis or psoriasis [14].

Biosimilar versions of several drugs, including recombined glucagon, recombined salmon calcitonin and hyaluronidase have been also admitted to the United States market.

\section{Biosimilar insulin - will they dominate the insulin market?}

A steady increase in the incidence to diabetes mellitus is observed in the world, in particular diabetes mellitus type 2 - the disease of civilization. After the 90's, since insulin was discovered, the insulin market is significant and it growths vigorously. It was estimated that the worldwide insulin sales amounted to $\$ 16.7$ billion in 2011, about $12,5 \%$ more than in 2010 . This sum exceeded $\$ 8.3$ billion in the USA and it has increased by $14.9 \%$ since 2010 [15]. The costs of treating diabetes are very high. In 2011, they exceeded $\$ 201$ billion in the United States and $\$ 465$ billion around the world [16]. The cost of insulin therapy constitutes a great part of all expenditures associated with the treatment of patients with type 1 and type 2 diabetes mellitus. Therefore, it seems that the biosimilar insulin can be the future of diabetes treatment.
The patent protection of numerous insulins, including short-acting and long-acting equivalents, such as insulin aspart, lispro and glargine expired or will expire in the near future.

Biosimilar insulins are biological modifications in which, the active substance is obtained from a living organism by DNA recombination methods or methods of control of gene expression. Any doubts that the biosimilar insulin is not a generic insulin should be dispelled, contrary to what some practitioners think. The differences between the generic and biosimilar insulin can be the same, as described above with regard to the generic and biosimilar products as such. The remarks concerning the safety of biosimilar insulin are of vital importance; immunogenicity (a significant issue in case of a chronic use of the product) and side effects, e.g. a risk of hypoglycaemia, disproportionate to the dose of the medicine.

In some countries that do not comply with the European standards, biosimilar copies of insulin are already widely available, e.g. Basalog based on the original drug - glargine, produced by Biocon in India, with the efficacy and safety similar to Lantus in patients with diabetes mellitus type 1 [17]. Biosimilar insulins are also used in China, Pakistan, Peru, Thailand and Mexico. In these countries, there are no special restrictions concerning marketing the biosimilar products.

In 2007, Marvel Lifesciences Private Ltd. (Mumbai, India) started its endeavours to obtain an approval of EMA (European Medicines Agency) for three biosimilar insulins: fast-acting insulin (Marvel Rapid), long-acting isophane insulin (Marvel Long) and mix (30\% of soluble insulin and $70 \%$ of long-acting insulin). However, the documentation submitted by the manufacturer was not complete. There was no exact specification of these insulins. Subsequently, Marvel withdrew from the registration procedure concerning these products.

A biosimilar drug Abasaglar is available in the European Union (the former name was Abasria; the name was changed in 2014 to Abasaglar) and it contains an active substance - insulin glargine. The European Medicines Agency (EMA) issued a positive opinion on this product in September 2014 [18]. The reference medicine for Abasaglar is insulin Lantus. The method of DNA recombination is used for production of the active substance of Abasaglar. It is created by bacteria to which a gen (DNA) that enables production of glargine was introduced. A case of a patient who has been taking glargine for years without any allergic reaction and who had anaphylaxis after taking biosimilar insulin was described in 2014. Basophil degranulation in vitro caused by a biosimilar product suggests the occur- 
rence of allergic reactions to one or more ingredients of the biosimilar drug, but not the parent one. After discontinuation of the biosimilar drug treatment and taking back the previously used glargine, the allergic reaction of the patient completely subsided. It proves the immunogenicity of the biosimilar drug [19].

It seems that the benefits of using biosimilar insulin, in particular a lower cost of therapy, outweigh the risk of any possible side effects. Nevertheless, lack of long-term randomized, blinded, trials constitutes a great problem. Unfortunately, there is no evidence based medicine on the efficacy and safety of using biosimilar insulins, so far. Most of the available publications on the subject matter were sponsored by pharmaceutical companies producing insulin. The companies frequently underestimate the need for a thorough and transparent interpretation of results of clinical researches. In case of insulin, the safety of the product is hard to be assed based on the animals testing, and what is more, on the basis of in vitro studies. The European Medicines Agency requires clinical tests in humans for registration purposes. On the one hand, it increases the safety of a product and on the other hand, it limits the number of drugs released. It is clear that the most desirable would be clinical studies comparing the efficacy and safety of a biosimilar drug with the original medicine.

In the coming years, most of patent agreements for the production of human insulins will expire. It will fully open the medical market to biosimilar insulins as an alternative to the original products. Abasaglar (named Basaglar in the USA) is produced by Eli Lilly and Boehringer Ingelheim, however it is well-known that other pharmaceutical concerns, such as Merck, Biocon (Mylan) and Sanofi are already working on biosimilar insulins (glargine, lispro). In the next few years, at least several biosimilar insulins will be available on the market. It is estimated that ultimately, about 40 biosimilar insulin will be put on the market [20].

\section{Summary}

With spreading the use of biosimilar insulins, it will be possible to lower the costs of treatment, increase the availability of insulin therapy among patients with type 1 and type 2 diabetes mellitus, and the choice of medicines will be large. Nevertheless, due to the safety of patients, the rules for the registration of biosimilar insulins and monitoring their side effects should be clearly defined and strictly observed. Long-term observations of not only the efficacy but also the safety of biosimilar products (including insulins) are required. Clinicians who deal with insulin therapy every day should be aware of both the advantages and disadvantages (in particular, the potential immunogenicity) of biosimilar insulins. The term "biosimilar drugs" is a mental shortcut meaning in fact "biological drugs registered on the basis of proving the biological similarity to the reference drug". Therefore, we should always remember that biosimilar drugs are not bioidentical with the originals.

\section{REFERENCES}

1. Commission Directive 2003/63/EC of June 2003 amending Directive 2001/83/EC of the European Parliament and Council on the Community code relating to medicinal products for human use.

2. Zieliński W. Biotechnologia. Monografie 2009; 5: 57-74.

3. Bogiel M, Marzec A. Leki biopodobne - pełnowartościowe, nowoczesne preparaty biotechnologiczne. Terapia i Leki 2008; 35/57/2: 40-50.

4. Lanao JM, Briones $\mathrm{E}$, Colino $\mathrm{Cl}$. Recent advances in delivery systems for anti-HIV1 therapy. J Drug Target 2007; 15: 21-36.

5. Sekhon BS, Saluja V. Biosimilars : an overview. Biosimilars 2011; 1: 1-11.

6. Roger SD. Biosimilars: current status and future directions. Expert Op Biol Ther 2010; 10: 1011-1018.

7. Kresse GB. Biosimilars - science, status, and strategic perspective. Eur J Pharm Biopharm 2009; 72: 479-486.

8. Nowicki M, Zimmer-Nowicka J. Biofarmaceutyki oryginalne i leki biopodobne - co należy o nich wiedzieć, aby zapewnić bezpieczeństwo leczenia? Onkol Prakt Klin 2007; 3: 120-127.

9. Schmidt CA, Ramos AS, da Silva JEP, Fronza M, Dalmora SL. Activity evaluation and characterization of recombinant human erythropoietin in pharmaceutical products. Arg Bras Endocrinol 2003; 47: 183-189.

10. Schellekens H. Follow-on-biologics: challenges of the "next generation". Nephrol Dial Transplant 2005; 20 (suppl 4): iv31-36.

11. Schellenkens $\mathrm{H}$. Biopharmaceuticals and biosimilars, unraveling the complexity. EJHP Practice 2006; 12: 13.

12. Crommelin D, Bermejo T, Bissig M et al. Biosimilars, generic versions of the first generation of therapeutic proteins: do they exist? Contributions to Nephrology 2005; 149: 287-294.

13. Crommelin DJ, Storm G, Verrik R, de Leede L, Jiskoot W, Hennink WE. Shifting paradigms: biopharmaceuticals versus low molecular weight drugs. Int J Pharmaceutics 2003; 266: 3-16.

14. EMA 2013. http://www.ema.europa.eu/ema/index. jsp?curl=pages/medicines/002778/human_med_001677. jsp\&mid=WCOb01ac058001d124.

15. Diabetes drug and device industry $1 \mathrm{Q} 12$ finacial model. San Francisco, Calif., Close Concerns, Inc. 2012.

16. International Diabetes Federation: Healthcare expenditures. http://www.idf.org/diabetesatlas/5e/healthcare-expenditures [dostęp: 17.06.2012].

17. Biocon. Biocon launches BASALOG - long lasting basal insulin for type 1\&type2 diabetics. http://www.biocon.com/biocon_inv_ press relaeses 29may2009.asp [dostęp: 04.2015].

18. European Commission grants Lilly and Boehringer Ingleheim's insulin glargine product marketing authorization in Europe. Press release of Eli Lilly and Boehringer Ingelheim, September 10, 2014. http://www.boehringeringelheim.com/news/news_releases/ /press relaeses/2014/10 september 2014 insulin glargine.html.

19. Garcia-Nares H, Leyva-Carmona MI, Perez-Xochipa N et al. A hypersensitivity reaction to a biosimilar insulin glargine. J Diabetes 2014; 7: 155-157.

20. Rader RA. An analysis of the US biosimilars development pipeline and likely market evolution. Bio Process Int 2013; 11: 16-23. 